\title{
LIVROS DIGITAIS E ENSINO SUPERIOR: REVISÃO DE LITERATURA
}

\author{
DIGITAL BOOKS AND HIGHER EDUCATION: LITERATURE REVIEW
}

\author{
Juliani Menezes dos Reis \\ Bibliotecária - UFRGS. \\ Doutoranda em Educação \\ juliani.reis@gmail.com \\ Luciana Backes \\ Doutora em Educação \\ Professora do Programa de Pós-graduação em Educação \\ Universidade La Salle - Canoas \\ luciana.backes@unilasalle.edu.br
}

Recebido em: 17-03-2019

Aceito em: 05-06-2019

\begin{abstract}
Resumo: Este artigo apresenta uma revisão de literatura realizada a partir do levantamento de teses e dissertações englobando os termos: livro digital, biblioteca digital, professores, livro digital na educação e ensino superior. A abordagem metodológica foi o levantamento bibliográfico das pesquisas identificadas na Biblioteca Digital de Teses e Dissertações (BDTD) e defendidas no período de 2003 a 2015, no Brasil. Os resultados obtidos demonstram a baixa incidência de pesquisas acadêmicas relacionando o livro digital, a biblioteca digital e ensino superior. As pesquisas realizadas por pesquisadores brasileiros em nível de dissertação e tese dizem respeito ao livro digital, biblioteca digital, leitura digital, uso de tablets em bibliotecas, uso de tecnologias digitais nas práticas pedagógicas de professores e criação de bibliotecas digitais.
\end{abstract}

Palavras-chave: Biblioteca Digital. Livro Digital. Ensino Superior. Livro Digital na Educação.

\begin{abstract}
This article presents a review of the literature carried out from the collection of theses and dissertations encompassing the terms: eBook, digital library, teachers, eBook in education and higher education. The methodological approach was the bibliographic survey of the researches identified in the Digital Library of Theses and Dissertations and defended in the period from 2003 to 2015, in Brazil. The results obtained demonstrate the low incidence of academic research relating the eBook, the digital library and higher education. The research carried out by Brazilian researchers at dissertation and thesis level refers to the digital book, digital library, digital reading, use of tablets in libraries, use of digital technologies in teachers' pedagogical practices and creation of digital libraries.
\end{abstract}

Keywords: Digital Library. eBook. Higher education. eBooks in Education.

\section{INTRODUÇÃO}

A proposta deste artigo é apresentar uma revisão de literatura originada do levantamento realizado na dissertação intitulada "O uso dos e-books por professores de universidades federais: novos olhares sobre as bibliotecas", no programa de Pós-Graduação em Educação, na Universidade La Salle. A dissertação foi desenvolvida no contexto da linha de pesquisa: Culturas, linguagens e tecnologias na Educação e do grupo de pesquisa COTEDIC UNILASALLE/CNPq.

A pesquisa transita pelas áreas da Educação e Biblioteconomia realizando um diálogo e apontando teses e dissertações relacionadas aos termos: livro digital, biblioteca digital (BD), professores, livro digital na educação e ensino superior, realizadas no período de 2003 a 2015, no Brasil. A abordagem metodológica foi 
o levantamento bibliográfico das pesquisas identificadas na Biblioteca Digital de Teses e Dissertações (BDTD).

Segundo Castells (2008), os registros históricos indicam que quanto maior for a relação entre os locais de inovação, produção e utilização das tecnologias, mais rápida será a transformação das sociedades e o retorno positivo das condições sociais que favorecerão futuras inovações. Observamos que essa relação ocorre frequentemente nas universidades devido à proximidade com as inovações tecnológicas, como por exemplo as tecnologias digitais. Às vezes, essas inovações são criadas dentro das paredes das universidades e elas são as primeiras a utilizar, como no caso da internet (MOSÉ, 2013). As universidades - tradicionalmente consideradas instituições do saber -, existentes desde a Idade Média, possibilitaram o desenvolvimento científico e intelectual e, posteriormente, na Idade Contemporânea, contribuíram para o desenvolvimento tecnológico.

Dessa forma, apresentar a produção acadêmica, produto das pesquisas acadêmicas na pós-graduação das universidades brasileiras, no que tange as bibliotecas digitais, ao livro digital e a Educação no contexto do ensino superior é o objetivo deste artigo. Para tanto, apresentamos o referencial teórico a respeito das temáticas educação e tecnologias digitais, biblioteca digital e livro digital, bem como os resultados obtidos no levantamento bibliográfico.

\section{REFERENCIAL TEÓRICO}

A biblioteca digital e o livro digital no contexto da Educação apresentam-se como inovações das últimas décadas, inseridos no emaranhado da sociedade em redes. São recursos proporcionados e viabilizados a partir da evolução das tecnologias digitais e que se tornaram imprescindíveis no ambiente acadêmico, principalmente no ensino superior com o avanço de disciplinas à distância.

\subsection{EDUCAÇÃO E TECNOLOGIAS DIGITAIS}

As reconfigurações da sociedade e do mundo a partir das tecnologias da Informação e Comunicação (TIC) e as inovações tecnológicas refletem também na Educação, nas relações na escola, entre alunos e professores. A existência de um mundo conectado e em rede repercute na maneira de trabalhar nas universidades e escolas, nas formas de ensinar e aprender.

Nas universidades surge uma combinação de modalidades de educação, on-line (a distância) com a educação in loco (presencial), indicando que o futuro do ensino superior será não somente em redes entre nós de informática, nas salas de aula, mas também no local onde os alunos estiverem (CASTELLS, 2008).

As tecnologias digitais estão alterando as relações econômicas, sociais e culturais. Esses fatores contribuem para a redução de custos no acesso à educação, contudo, em relação à cibercultura, além da transição da modalidade presencial para à distância (on-line), ou do escrito e oral para a multimídia, ocorre a transição da educação e formação estritamente institucionalizada (com a escola e a universidade) para uma situação de compartilhamento generalizado de saberes. Nesse compartilhamento, acontece a educação da 
sociedade por ela mesma, de reconhecimento auto gerenciado, móvel e contextual das competências (LÉVY, 2010).

Bisol (2010, p. 23) aponta que "A entrada de nossa civilização em um novo estágio de desenvolvimento traz, necessariamente, mudanças na formalização do ensino [...]”. É o que ocorre com os ambientes virtuais de aprendizagem e as novas modalidades de educação a distância (on-line), possíveis através da internet e do computador. Essas mudanças ocorrem também nas relações entre professores e alunos, nas interações, na constituição da subjetividade e na forma de apropriação do conhecimento (BISOL, 2010).

Algumas reflexões são necessárias: "[...] de um lado é preciso educar para uma sociedade dita informatizada; de outro lado, é preciso utilizar a informática para educar.” (CEZAR, 2003, p. 88). É necessário refletir coletivamente, pois as tecnologias digitais já fazem parte de nossa sociedade e da educação, mas é preciso "[...] pensar nas tecnologias PARA a Educação [...]” (AXT, 2000, p. 56). Dessa forma, será possível construir conhecimentos e não apenas repassar informações. Novas formas de conviver e de pensar estão sendo elaboradas no mundo das telecomunicações e da informática, nas relações entre os seres humanos, a própria inteligência e o trabalho estão ligadas à metamorfose constante de dispositivos informacionais de diversos tipos e modelos (LÉVY, 2004).

Conforme indica Carvalho (2004), no universo cultural humano coexistem uma variedade de espaçostempos, não sendo possível destruir o velho para fazer emergir o novo. A tecnologia surge como mediadora entre a natureza e o homem, e, embora não possua neutralidade ou autonomia, ela cria novas possibilidades para o homem, cabendo a ele discernir entre as possibilidades que instituem estratégias de dominação ou de libertação (CARVALHO, 2004). Em vista disso, mais do que servir como suporte às necessidades da sociedade, as tecnologias digitais podem contribuir no desenvolvimento do potencial cognitivo, criativo, humano e na mediação pedagógica em sala de aula, como recurso educacional de apoio.

Neste contexto, surgem as bibliotecas digitais como recursos a serem explorados tanto em universidades, quanto em escolas, em salas de aulas presenciais ou virtuais, auxiliando nos processos de ensino e de aprendizagem.

\subsection{BIBLIOTECA DIGITAL}

A biblioteca, instituição social mais antiga que a própria universidade, também é atingida pelas mudanças do mundo contemporâneo e busca adaptar-se aos desafios da sociedade em redes, conforme observamos com o desenvolvimento das bibliotecas digitais e a ocorrência das bibliotecas híbridas. Conforme explana Lucas:

O progresso tecnológico mudou a maneira de as bibliotecas realizarem as suas atividades, mas não a razão de ser das bibliotecas, isto é, oferecer um conjunto organizado de informações afins, armazenadas com o objetivo de consulta ou utilização posterior. Neste contexto, ressaltamos que o importante é valorizar a natureza do conceito de Biblioteca, entendida como coleção pública ou privada de livros e documentos congêneres, organizada para estudo, leitura e consulta, nas emergentes Bibliotecas Digitais (LUCAS, 2004, p. 16). 
Neste contexto, estão as bibliotecas digitais que, na literatura, apresenta discussões teórico-conceituais há mais de 50 anos - sobre a conceituação dos termos biblioteca digital, biblioteca eletrônica, biblioteca virtual, bibliotecas sem paredes, biblioteca em rede, biblioteca lógica e biblioteca do futuro, entre outros (BEZERRA, 2003; HOMMERDING, 2007; LUCAS, 2004; SÁ, 2013). Não há consenso, contudo, em relação à polissemia dos termos, ponderamos que esses conceitos não são caixas fechadas que serão classificadas, pois estão articulados entre si e, em alguns momentos, notamos que um conceito invade o espaço do outro. Buscamos diferenciar os termos a partir da literatura encontrada na área de Biblioteconomia.

Cunha (1997, p. 2) relata que "A biblioteca digital é também conhecida como biblioteca eletrônica (principalmente no Reino Unido), biblioteca virtual (quando utiliza recursos da realidade virtual), biblioteca sem paredes e biblioteca cibernética.". O termo virtual vem do latim virtualis, de virtus, que significa força ou potência (LEMOS, 2003).

O rápido avanço tecnológico das bibliotecas digitais e sua consequente interdisciplinaridade provocou interesse em pesquisadores de diversas áreas do conhecimento, que trazem múltiplas perspectivas ao seu desenvolvimento (HOMMERGIND, 2007). Já para Benício e Silva (2005), as bibliotecas sem paredes “[...] reúnem suportes não-convencionais e facilitam a disseminação da informação em tempo real. Esses sistemas podem ser classificados em quatro categorias: biblioteca eletrônica, digital, virtual e híbrida.”. Apresentamos a seguir a nomenclatura mais usual relacionada aos tipos de bibliotecas, consideramos que as bibliotecas sem paredes englobam as bibliotecas eletrônica, digital e virtual.

Em relação a biblioteca eletrônica, o termo é utilizado há mais de 30 anos para definir uma biblioteca informatizada com os equipamentos necessários ao seu funcionamento, sendo eles computadores, terminais de acesso e catálogo automatizado (REIS, 2013; TAMMARO; SALARELLI, 2008). O computador é utilizado para armazenar, recuperar e disponibilizar acesso a informações disponíveis on-line (textos completos), em outras bibliotecas e em rede (CAVALCANTI; CUNHA, 2008; LANDONI; CATENAZZI; GIBB, 1993; ROSETTO, 2008; ROWLEY, 2002). Não são consideradas bibliotecas digitais, pois apenas possuir equipamentos eletrônicos não a caracteriza a realiação de empréstimos de livros digitais (REIS, 2013).

A biblioteca digital se caracteriza por estar disponível em qualquer hora e em qualquer lugar. Intensificam o conceito de compartilhamento de recursos provenientes das bibliotecas tradicionais e destinamse a comunidades de usuários (SAYÃO, 2009). Existem apenas em formato digital, ou seja, contêm a informação apenas em formato digital (ROSETTO, 2008).

O termo biblioteca virtual foi cunhado por Tim Bernes-Lee, mais antigo que o termo biblioteca digital e que foi muito utilizado para definir o novo conceito de biblioteca, “[...] materializa a visão de uma biblioteca como uma coleção de documentos ligados em rede, constituídos por objetos digitais e páginas Web produzidos por milhares de autores.” (TAMMARO; SALARELLI, 2008, p. 117). A expressão biblioteca virtual se refere a coleções selecionadas de vínculos com sites da Rede para representar o espaço físico e lógico de coleções de documentos fora da biblioteca, de forma mais ampla que as definições de biblioteca eletrônica e digital 
(TAMMARO; SALARELLI, 2008). Levacov (2003, p. 249) afirma que "A biblioteca virtual, com frequência, aponta para as fontes de informação sem, necessariamente, possuir a propriedade física das mesmas.”, podendo utilizar realidade virtual para realizar suas interações (ROSETTO, 2008). Para Tomaél et al. (2001, p. 3) "O termo biblioteca virtual, é um bom exemplo da dificuldade de conceituação das novas fontes. Basta consultar a literatura a respeito para verificar as várias acepções que o termo tem assumido.".

A biblioteca digital (BD) assemelha-se à biblioteca física ou tradicional, podemos dizer que as imita, tendo em vista ser um conjunto organizado de livros ou uma coleção organizada de informações em formato digital e acessível pela rede mundial de computadores. Essa biblioteca, assim como a biblioteca física, precisa de gestão e organização de suas coleções, bem como de um espaço geograficamente localizado para a realização das atividades tradicionais de registro, classificação e indexação do material bibliográfico. A BD deve viabilizar o acesso à informação em meio digital, proporcionando sua democratização e a inclusão social e cultural (ROSETTO, 2008).

\subsection{LIVRO DIGITAL}

Diversas mudanças ocorreram com o livro. O livro evoluiu, acompanhando e se reconfigurando a partir das mudanças na sociedade e pelas tecnologias digitais. Para entender o livro digital, é importante compreender a trajetória do livro ao longo da História da humanidade. Barrios e Queiroz (2013, p. 1-2, grifos do autor) resumem esse caminho percorrido:

As diversas mudanças nos formatos de registro de informação decorrem de um processo que vem ocorrendo há centenas de anos. O livro, vislumbrado como suporte informacional, pode ser considerado como um dos mais antigos meios de registro de informação. Ao longo de milhares de anos, o livro passou por diversas mudanças em seu formato: tabletes de argila, rolo (volumen), códice (codex), incunábulos, in folio, até a criação dos e-readers (electronics readers ou leitores eletrônicos), e-books (electronics books ou livros eletrônicos), também podendo ser citado o papel eletrônico.

Assim, pode ser interpretada como uma evolução a forma de apresentação do "novo" livro hoje, conhecido como e-book.

O e-book (eletronic book) é o termo em inglês usado para definir o livro em formato eletrônico, diz respeito a uma publicação em formato digital que pode incluir texto, imagens, vídeo e áudio (BENÍCIO, 2003; PINHEIRO, 2011). Livro digital, livro eletrônico, e-book, e-livro são outras nomenclaturas utilizadas para definir o livro em formado digital, criado exclusivamente em ambiente digital ou digitalizado (REIS, 2013). É importante definir o livro digital:

[...] o e-book, e-livro, livro eletrônico, digital ou virtual é um livro exclusivamente em formato digital, não periódico, que necessita de um aparelho leitor e de um software para decodificação que viabilize sua leitura. Pode conter texto, imagem, áudio e vídeo, permite a navegação, inclusão de comentários pelo leitor, marcação de trechos, bem como o controle e o ajuste de brilho, cor e tamanho da fonte. Em geral, a estrutura e a organização do livro digital se assemelha a do livro impresso, ou seja, contém capa, folha de rosto, sumário, capítulos, índices, glossário etc. Contudo, alguns elementos pré-textuais, como sumário e 
folha de rosto, e pós-textuais, como índices, podem ser ocultados, já que a possibilidade de pesquisar palavras dispensa esses elementos. No caso da folha de rosto, se a capa contiver as informações não é necessário tê-la (REIS, 2013, p. 30).

Para a realização da leitura do livro digital são necessários aparelho leitor, e-reader e software específico para decodificar o arquivo, denominado de reader (REIS, 2013). O aparelho leitor ou e-reader é o aparelho específico para leitura, mas também podem ser utilizados dispositivos portáteis, computador de mesa, notebook, smartphone, tablet, entre outros (ARAÚJO et al., 2013; REIS, 2013). Existem diversos formatos de arquivo utilizados nos softwares de leitura no mercado, como o PDF, Epub, Mobi, Rb, TPZ, Pdb, AZW, LIT, OBE, entre outros e para cada formato de arquivo é necessário um software específico para edição e leitura (ARAÚJO et al., 2013; REIS, 2013).

As alterações na sociedade contemporânea provocam mudanças nas formas de ler e construir textos, criando uma cultura de leitura digital, conforme explana Casalegno (2003, p. 275):

\begin{abstract}
Os leitores podem folhear textos conectados, citados e comentados de forma metodológica, mas não sequencial. A multiplicidade das funções do hipertexto necessita, portanto, de um leitor ativo, capaz de ligar os diferentes materiais disponíveis. O leitor não segue mais um texto, mas escolhe um percurso de leitura e, num segundo tempo, pode tomar notas, escrever os seus comentários e enviar mensagens, as quais podem tornar-se textos de confirmação ou contestação do material de base. Mas o fato de ter de escolher o trajeto pode desestabilizar os leitores sem experiência.
\end{abstract}

Benício (2003, p. 57) menciona que “[...] a revolução dos livros eletrônicos será também a revolução da leitura, haja visto que, ler sobre uma tela não é ler um códex.". Tudo isso causa impacto na vida das pessoas, seja na vida pessoal ou profissional, como usuários ou leitores, que precisam se adaptar aos novos tempos (BENÍCIO, 2003). A esse respeito, Lévy (2010, p. 59) comenta:

Em relação às técnicas anteriores de ajuda à leitura, a digitalização introduz uma pequena revolução copernicana: não é mais o navegador que segue os instrumentos de leitura e se desloca fisicamente no hipertexto, virando as páginas, deslocando volumes pesados, percorrendo a biblioteca. Agora é um texto móvel, caleidoscópico, que apresenta suas facetas, gira, dobra-se e desdobra-se à vontade frente ao leitor.

O hipertexto provoca mudanças na forma de ler e escrever e, por vezes, leitura e escrita trocam de papéis (LÉVY, 2010). Nas palavras de Levy (2010, p. 64) “Com o hipertexto, toda leitura é uma escrita potencial.". Vale ressaltar que no livro impresso o leitor consegue visualizar integralmente e linearmente o texto, já no suporte digital, a leitura em tela preliminar e linear não está presente. Contudo, o leitor em tela é mais ativo devido à interatividade possível nos suportes digitais (LÉVY, 2007).

\title{
3 ABORDAGEM METODOLÓGICA
}

Descrevemos neste capítulo o caminho percorrido no levantamento de teses e dissertações relacionados ao livro digital e suas variantes, à educação, ensino superior e às bibliotecas digitais. $\mathrm{O}$ levantamento bibliográfico foi realizado no primeiro semestre de 2015, na Biblioteca Digital de Teses e 
Dissertações (BDTD), do Instituto Brasileiro de Ciência e Tecnologia (IBICT). Também foi criado um alerta no Google Alerts para os termos 'Livro Digital', 'E-books' e 'Bibliotecas Digitais' a fim de recuperar teses e dissertações atualizadas durante o momento da coleta.

As estratégias de busca utilizadas no levantamento de teses e dissertações realizado na BDTD englobaram os seguintes descritores: 'Biblioteca Digital', 'Livro Digital', 'Professores e Livros Digitais', 'Ensino Superior e Bibliotecas Digitais' e 'Livro Digital na Educação'. Definimos não utilizar o termo 'Tecnologias Digitais' em virtude da amplitude do tema e ao excesso de trabalhos recuperados não vinculados à pesquisa. Foram utilizadas as variantes ' $e$-book' e 'livro eletrônico' para o termo 'livro digital', bem como o singular e plural dos demais termos e operadores booleanos (AND, NOT, OR) na estratégia de busca. Não se delimitou o período de tempo inicial na pesquisa devido à constatação de escassez de material, mas, como limite máximo, foi definido o ano de 2015, desconsiderando pesquisas posteriores.

\subsection{ANÁLISE DOS DADOS EMPÍRICOS}

Ao pesquisar pelo termo 'Bibliotecas Digitais' recuperamos 22 resultados, dos quais 6 foram selecionados e se encontram listados no Quadro 1. Alguns estudos foram descartados por tratarem exclusivamente da BDTD como assunto, de textos digitais ou por pertencerem a áreas distintas aos objetivos da pesquisa. A busca pelo termo 'Livro Digital' resultou em 13.421 documentos. Para restringir os resultados realizamos uma nova pesquisa refinando na aba 'Busca Avançada', na opção 'Título'. Nessa busca, recuperamos apenas uma dissertação que está relacionada no Quadro 1. Tendo em vista o baixo número de resultados, pesquisamos também na opção 'Resumo', obtendo 10 resultados, dos quais 5 foram selecionados.

A busca pelos descritores 'Professores e Livros Digitais' resultou em 23 trabalhos, dos quais 2 foram selecionados, conforme a relevância do tema. A busca pelos termos 'Ensino Superior e Bibliotecas Digitais' resultou em 189 documentos, contudo, muitos eram relacionados à mídias digitais na educação, à educação a distância ou aos ambientes virtuais de aprendizagem e, por esse motivo, foram descartados, apenas 2 trabalhos foram selecionados. O termo de busca 'Livro Digital na Educação' resultou em 1980 documentos, porém, esses documentos se relacionavam com as palavras 'livro', 'digital' ou 'educação', não havendo correlação entre os três termos, sendo assim, nenhum documento relevante foi recuperado.

O Quadro 1 apresenta as teses e dissertações selecionadas a partir da avaliação dos seguintes dados: título do trabalho, assuntos encontrados nas palavras-chave do resumo, resumo, sumário, além de leitura técnica do estudo. 
Quadro 1 - Levantamento de Teses e Dissertações

\begin{tabular}{|c|c|c|c|c|c|}
\hline Termo & $\mathrm{D} / \mathrm{T}$ & Ano & Autor & Título & Descrição \\
\hline \multirow{6}{*}{ 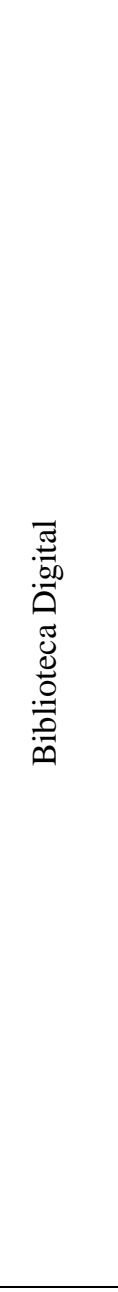 } & $\begin{array}{l}\stackrel{0}{\infty} \\
\stackrel{\leftrightarrow}{\Leftrightarrow}\end{array}$ & ॄ্ণ & $\begin{array}{l}\text { Hommerding, } \\
\text { Nadia Maria } \\
\text { dos Santos }\end{array}$ & $\begin{array}{l}\text { Em busca da avaliação de } \\
\text { bibliotecas digitais: caminhos } \\
\text { e descaminhos }\end{array}$ & $\begin{array}{l}\text { Analisa duas bibliotecas digitais } \\
\text { através de critérios de avaliação, } \\
\text { destacando a necessidade da } \\
\text { efetivação desse processo de } \\
\text { avaliação a fim de promover } \\
\text { melhorias e ajustes. }\end{array}$ \\
\hline & \multirow{5}{*}{ 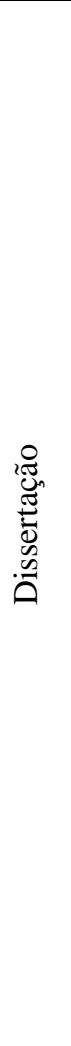 } & 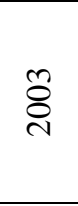 & $\begin{array}{l}\text { Bezerra, Emy } \\
\text { Pôrto }\end{array}$ & $\begin{array}{l}\text { Digitalizando o virtual: uma } \\
\text { análise informacional do } \\
\text { processo de implementação } \\
\text { da biblioteca Digital Paulo } \\
\text { Freire }\end{array}$ & $\begin{array}{l}\text { Através de um estudo de caso, com } \\
\text { entrevistas e grupo focal, analisa a } \\
\text { fase inicial da implantação da } \\
\text { Biblioteca Digital Paulo Freire. }\end{array}$ \\
\hline & & $\stackrel{\circ}{\circ}$ & $\begin{array}{l}\text { Lira, Roseane } \\
\text { Barros da Silva }\end{array}$ & $\begin{array}{l}\text { Educação de Jovens e Adultos } \\
\text { e a formação de } \\
\text { professores(as): o uso de uma } \\
\text { biblioteca digital como } \\
\text { ferramenta de aprendizagem }\end{array}$ & $\begin{array}{l}\text { Propõe a organização de uma } \\
\text { Biblioteca Digital voltada para a } \\
\text { Educação de Jovens e Adultos } \\
\text { (EJA) e sua contribuição a alunos e } \\
\text { professores. }\end{array}$ \\
\hline & & $\overline{\bar{i}}$ & $\begin{array}{l}\text { Landshoff, } \\
\text { Renate }\end{array}$ & $\begin{array}{l}\text { Findability: elementos } \\
\text { essenciais para as formas de } \\
\text { encontro da } \\
\text { informação em Bibliotecas } \\
\text { Digitais }\end{array}$ & $\begin{array}{l}\text { Aborda a avaliação da recuperação } \\
\text { da informaça em Bibliotecas } \\
\text { Digitais. Analisa duas bibliotecas } \\
\text { digitais em profundidade. }\end{array}$ \\
\hline & & $\stackrel{\widetilde{\imath}}{\tilde{i}}$ & $\begin{array}{l}\text { Fonseca, } \\
\text { Leandro } \\
\text { Guedes da }\end{array}$ & $\begin{array}{l}\text { Biblioteca virtual temática } \\
\text { em saúde focada nas } \\
\text { necessidades do usuário e na } \\
\text { usabilidade }\end{array}$ & $\begin{array}{l}\text { Realiza levantamento de } \\
\text { características de usabilidade } \\
\text { aplicadas à bibliotecas virtuais a } \\
\text { partir de um estudo de caso, } \\
\text { utilizando entrevistas e grupo focal. }\end{array}$ \\
\hline & & $\underset{\sim}{\vec{d}}$ & $\begin{array}{l}\text { Andrade, } \\
\text { Robéria de } \\
\text { Lourdes de } \\
\text { Vasconcelos }\end{array}$ & $\begin{array}{l}\text { Ferramentas web para } \\
\text { construção de uma biblioteca } \\
\text { pública digital livre }\end{array}$ & $\begin{array}{l}\text { Estuda ferramentas gratuitas para o } \\
\text { desenvolvimento e implantação de } \\
\text { uma biblioteca digital para } \\
\text { bibliotecas públicas. Aplica um } \\
\text { questionário e desenvolve um } \\
\text { protótipo de DB pública. } \\
\end{array}$ \\
\hline \multirow{4}{*}{ 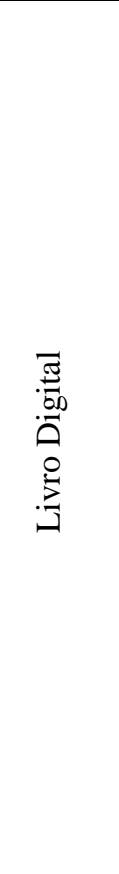 } & $\begin{array}{l}\mathscr{E} \\
\stackrel{0}{\oplus}\end{array}$ & $\underset{⿱ 亠}{\check{\lambda}}$ & $\begin{array}{l}\text { Duarte, } \\
\text { Marcos } \\
\text { Nepomuceno }\end{array}$ & $\begin{array}{l}\text { O livro como espetáculo: } \\
\text { transformações do campo } \\
\text { editorial com o advento dos } \\
\text { e-books }\end{array}$ & $\begin{array}{l}\text { Aborda o mercado editorial de } e \text { - } \\
\text { books, no contexto brasileiro, a } \\
\text { partir de mudanças nesse mercado } \\
\text { causadas pelas TIC, e as } \\
\text { transformações do hábito de leitura. }\end{array}$ \\
\hline & \multirow{3}{*}{ 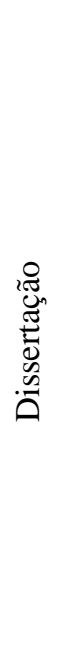 } & $\stackrel{\Im}{i}$ & $\begin{array}{l}\text { Almeida, } \\
\text { Lemilson José } \\
\text { Cavalcanti de }\end{array}$ & $\begin{array}{l}\text { O livro digital no mundo } \\
\text { editorial e a evoluçãa } \\
\text { histórica do copyright e das } \\
\text { estratégias de apropriação de } \\
\text { lucro }\end{array}$ & $\begin{array}{l}\text { Pesquisa a indústria editorial, o } \\
\text { direito autoral e a regulação do } \\
\text { copyright em quatro países: Brasil, } \\
\text { Estados Unidos, França e Reino } \\
\text { Unido. }\end{array}$ \\
\hline & & $\stackrel{m}{\grave{i}}$ & $\begin{array}{l}\text { Escalante, } \\
\text { Simone } \\
\text { Bordallo de } \\
\text { Oliveira }\end{array}$ & $\begin{array}{l}\text { O uso do tablet como recurso } \\
\text { de apoio ao processo de } \\
\text { ensino e aprendizagem: a } \\
\text { percepção de jovens e } \\
\text { professores do ensino médio }\end{array}$ & $\begin{array}{l}\text { Investiga a percepção de alunos do } \\
\text { Ensino Médio, de uma escola } \\
\text { particular, sobre o uso de tablets nas } \\
\text { atividades em sala de aula. Aborda } \\
\text { a informática na educação e a } \\
\text { influência das tecnologias no } \\
\text { ambiente educacional. }\end{array}$ \\
\hline & & $\underset{\vec{d}}{\vec{d}}$ & $\begin{array}{l}\text { Silva, Edna } \\
\text { Cândida da }\end{array}$ & $\begin{array}{l}\text { A biblioteca, o livro e as } \\
\text { novas tecnologias: práticas de } \\
\text { leitura, memórias } \\
\text { conhecimento }\end{array}$ & $\begin{array}{l}\text { Contextualiza a Biblioteca ao longo } \\
\text { da História. Resgata a história da } \\
\text { escrita, do livro e dos livros digitais } \\
\text { e, abordando a leitura e tecnologias } \\
\text { da informação. }\end{array}$ \\
\hline
\end{tabular}




\begin{tabular}{|c|c|c|c|c|c|}
\hline & & 胥 & $\begin{array}{l}\text { Sehn, Thaís } \\
\text { Cristina } \\
\text { Martino }\end{array}$ & $\begin{array}{l}\text { As possíveis configurações } \\
\text { do livro nos suportes digitais }\end{array}$ & $\begin{array}{l}\text { Mapeia os livros digitais realizando } \\
\text { um resgate histórico e identificando } \\
\text { as características do livro e as } \\
\text { potencialidades do livro digital } \\
\text { como hipertexto, multimídia e } \\
\text { interatividade. }\end{array}$ \\
\hline \multirow{2}{*}{ 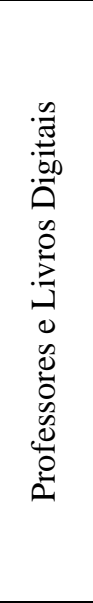 } & \multirow[b]{2}{*}{$\underset{\mathscr{B}}{\stackrel{0}{\oplus}}$} & $\stackrel{\text { ¿̊ }}{\circ}$ & $\begin{array}{l}\text { Ribeiro, Ana } \\
\text { Elisa Ferreira }\end{array}$ & $\begin{array}{l}\text { Navegar lendo, ler } \\
\text { navegando: aspectos do } \\
\text { letramento digital e da leitura } \\
\text { de jornais }\end{array}$ & $\begin{array}{l}\text { Aborda o letramento digital, mídias } \\
\text { mosaiquicas, objetos de leitura e } \\
\text { leitores a partir de um estudo de } \\
\text { caso com universitários. Analisa a } \\
\text { leitura de jornais impressos e } \\
\text { digitais. }\end{array}$ \\
\hline & & $\overline{\vec{i}}$ & $\begin{array}{l}\text { Martins, } \\
\text { Valéria Bussola }\end{array}$ & $\begin{array}{l}\text { O despertar para a leitura por } \\
\text { meio de mídias digitais }\end{array}$ & $\begin{array}{l}\text { Reflete sobre o papel do professor } \\
\text { de Língua Portuguesa do ensino } \\
\text { fundamental na formação de } \\
\text { leitores e expõe práticas } \\
\text { pedagógicas, calcadas em mídias } \\
\text { digitais, que se demonstraram } \\
\text { eficazes durante as aulas de leitura e } \\
\text { produção de texto, resultando em } \\
\text { novas formas de avaliação. }\end{array}$ \\
\hline \multirow{2}{*}{ 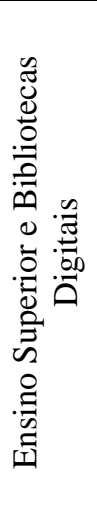 } & \multirow[t]{2}{*}{ 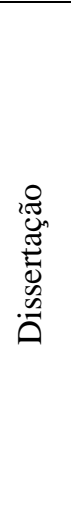 } & ఫౖ̊ & $\begin{array}{l}\text { Candaten, } \\
\text { Fernanda } \\
\text { Borguezan }\end{array}$ & $\begin{array}{l}\text { Trajetórias e saberes docentes } \\
\text { na concepção sobre uso de } \\
\text { tecnologias digitais no ensino } \\
\text { superior: o caso da URI - } \\
\text { Campus } \\
\text { De Frederico Westphalen/RS }\end{array}$ & $\begin{array}{l}\text { Investiga a constituição dos saberes } \\
\text { docentes em relação às tecnologias } \\
\text { nas práticas pedagógicas no ensino } \\
\text { superior e conclui que existe } \\
\text { necessidade de formação docente } \\
\text { para o uso de tecnologias visando a } \\
\text { construção de novos } \\
\text { conhecimentos. }\end{array}$ \\
\hline & & $\stackrel{\text { ¿̊ }}{\infty}$ & $\begin{array}{l}\text { Dias, } \\
\text { Mara }\end{array}$ & $\begin{array}{l}\text { Bibliotecas virtuais/digitais: } \\
\text { suas ferramentas e } \\
\text { contribuições na educação } \\
\text { superior: o caso da PUCPR }\end{array}$ & $\begin{array}{l}\text { Investiga as contribuições das } \\
\text { Bibliotecas virtuais e digitais para o } \\
\text { processo de ensino e aprendizagem } \\
\text { na PUCPR. Analisa a usabilidade } \\
\text { das bases de dados }\end{array}$ \\
\hline
\end{tabular}

Fonte: BDTD (2015).

Foram selecionados 15 trabalhos, sendo 3 teses e 12 dissertações defendidas no período de 2003 a 2014. Os estudos foram agrupados de acordo com o tipo de pesquisa (pesquisa documental e pesquisa de campo), conforme definição dos próprios autores. As pesquisas de campo, de abordagem qualitativa, utilizando estudo de caso, com questionários, entrevistas ou grupo focal, foram abordadas por Almeida (2012), Bezerra (2003), Candaten (2006), Fonseca (2012) e Hommerding (2007). Pesquisas quanti-qualitativas, utilizando estudo de caso e aplicação de questionário, entrevistas e/ou grupos focais, foram realizadas por Andrade (2014), Escalante (2013), Dias (2008) e Ribeiro (2008). Duarte (2014), Landshoff (2011), Lira (2010), Martins (2011), Sehn (2014), Silva (2014) realizaram pesquisas documentais, de abordagem qualitativa e análise documental.

Observamos nos trabalhos selecionados que as temáticas sobre o livro digital, bibliotecas digitais e o ensino superior tem sido preocupação de diversos pesquisadores que dedicaram à essas temáticas suas teses e dissertações. As pesquisas selecionadas apresentaram as diversas potencialidades do livro digital e da 
biblioteca digital mostrando suas peculiaridades e avanços na sociedade em rede. Contudo, nenhuma pesquisa havia sido realizada explorando o uso dos livros digitais e das bibliotecas digitais no ensino superior.

\section{CONSIDERAÇÕES FINAIS}

Com o ciberespaço surgiu um mundo virtual e a informação em fluxo, estabelecendo uma cultura da virtualidade real que reconfigura a sociedade da qual o livro digital faz parte. Todas essas mudanças influenciam nossas percepções e nossa forma de viver e conviver com os outros. Nossa rotina passa a ser envolvida e mediada por tecnologias digitais. No contexto acadêmico, verificamos que os professore, estudantes e pesquisadores estão habituados e familiarizados com o uso das tecnologias digitais e muitos leem artigos de periódicos em formato digital, buscam conteúdos na internet e conhecem as questões relacionadas ao direito autoral (como a pirataria, por exemplo). Consideramos que no decorrer do tempo, deve ocorrer também a familiarização com os livros digitais e entendemos que para isso é muito importante que haja o aumento da oferta de e-books e da divulgação nas instituições que o possuem. Assim, de forma cíclica (divulgação - uso - divulgação) será possível tornar a leitura digital em e-books uma atividade comum no ambiente acadêmico.

Nesse contexto, saber o que está sendo produzido nas universidades como produto das pesquisas acadêmicas na pós-graduação, no que tange as bibliotecas digitais, ao livro digital e a Educação no contexto do ensino superior é fundamental para nortear os futuros pesquisadores em suas pesquisas. Os resultados obtidos nesta revisão de literatura demonstram a baixa incidência de pesquisas acadêmicas relacionando o livro digital, a biblioteca digital e ensino superior, visto que apenas 15 pesquisas foram localizadas no período de 2002 a 2015.

Esta revisão de literatura apresentou as pesquisas realizadas por pesquisadores brasileiros em nível de dissertação e tese no que diz respeito ao livro digital, biblioteca digital, leitura digital, uso de tablets em bibliotecas, uso de tecnologias digitais nas práticas pedagógicas de professores, e até mesmo criação de bibliotecas digitais. Esses resultados, apesar de não serem numerosos, demonstram que essas temáticas tem perturbado os pesquisadores.

Apesar de serem temas atuais e recorrentes, destacamos que os pesquisadores e professores ainda precisam explorar o potencial dos livros digitais e das bibliotecas digitais em suas práticas pedagógicas, para que esses recursos não sejam subutilizados dentro das universidades. Sugerimos que um estreitamento da relação entre os professores, pesquisadores e as bibliotecas digitais e livros digitais pode instigar mudanças na cultura da leitura e da leitura digital no ambiente acadêmico. Além do aprofundamento de pesquisas relacionando o livro digital, a biblioteca digital e as práticas pedagógicas dos professores.

\section{REFERÊNCIAS}

ANDRADE, Robéria de Lourdes de Vasconcelos. Ferramentas web para construção de uma biblioteca digital livre. 2014. 164 f. Dissertação (Mestrado em Ciência da Informação) - Programa de Pós-Graduação 
em Ciência da Informação, Universidade Federal da Paraíba, João Pessoa, 2014. Disponível em: < https://repositorio.ufpb.br/jspui/handle/tede/3962 >. Acesso em: 11 jun. 2018.

ALMEIDA, Lemilson José Cavalcanti de. O livro digital no mundo editorial e a evolução histórica do copyright e das estratégias de apropriação de lucro. 2012. 367 f. Dissertação (Mestrado em Administração)- Departamento de Administração, Faculdade de Economia, Administração e Contabilidade, Universidade de São Paulo, São Paulo, 2012. Disponível em: <

http://www.teses.usp.br/teses/disponiveis/12/12139/tde-04042012-204431/pt-br.php>. Acesso em: 11 jun. 2018.

BEZERRA, Emy Pôrto. Digitalizando o virtual: uma análise informacional do processo de implementação da Biblioteca Digital Paulo Freire. 2003. 132 f. Dissertação (Mestrado em Ciência da Informação) - Centro de Ciências Sociais Aplicadas, Universidade Federal da Paraíba, João Pessoa, 2003. Disponível em: < https://repositorio.ufpb.br/jspui/handle/tede/3992>. Acesso em: 09 jun. 2018.

CANDATEN, Fernanda Borguezan. Trajetórias e saberes docentes na concepção sobre uso de tecnologias digitais no ensino superior: o caso da URI - Campus De Frederico Westphalen/RS. 2006. 205 f. Dissertação (Mestrado em Educação) - Universidade do Vale do Rio dos Sinos, São Leopoldo, 2006. Disponível em: < http://biblioteca.asav.org.br/vinculos/tede/trajetorias\%20e\%20saberes.pdf >. Acesso em: 13 jun. 2018.

CASTELLS, Manuel. A Sociedade em rede. 11. ed. São Paulo: Paz e Terra, 2008. (A Era da Informação: Economia, Sociedade e Cultura; v. 1.)

DUARTE, Marcos Nepomuceno. O livro como espetáculo: transformações do campo editorial com o advento dos e-books. 2014. 254 f. Tese (Doutorado em Educação) - Universidade Presbiteriana Mackenzie, São Paulo, 2014. Disponível em: < http://tede.mackenzie.br/jspui/handle/tede/2083 >. Acesso em: 11 jun. 2018.

ESCALANTE, Simone Bordallo de Oliveira. O uso do tablet como recurso de apoio ao processo de ensino e aprendizagem: a percepção de jovens e professores do ensino médio. 2013. 123 f. Dissertação (Mestrado em Educação)- Universidade Católica de Brasília, Brasília, 2013. Disponível em: < https://bdtd.ucb.br:8443/jspui/handle/tede/1986 >. Acesso em: 12 jun. 2018.

FONSECA, Leandro Guedes da. Biblioteca virtual temática em saúde focada nas necessidades do usuário e na usabilidade. Rio de Janeiro, 2012. 116 f. Dissertação (Mestrado em Ciência da Informação)Faculdade de Administração e Ciências Contábeis, Universidade Federal do Rio de Janeiro, Instituto Brasileiro de informação em Ciência e Tecnologia, Rio de Janeiro, 2012. Disponível em: < http://ridi.ibict.br/bitstream/123456789/776/1/fonseca2012.pdf >. Acesso em: 10 jun. 2018.

HOMMERDING, Nádia Maria dos Santos. Em busca da avaliação de bibliotecas digitais: caminhos e descaminhos. 2007. 217 f. Tese (Doutorado em Ciência da Informação) - Escola de Comunicação e Artes, Universidade de São Paulo, São Paulo, 2007. Disponível em: <

http://www.teses.usp.br/teses/disponiveis/27/27151/tde-20052009-140703/pt-br.php >. Acesso em: 09 jun. 2018

LANDSHOFF, Renate. Findability: elementos essenciais para as formas de encontro da informação em Bibliotecas Digitais. 2011. 127 f. Dissertação (Mestrado em Tecnologias da Inteligência e Design Digital)Pontifícia Universidade Católica de São Paulo, São Paulo, 2011. Disponível em: < https://sapientia.pucsp.br/handle/handle/18089 >. Acesso em: 11 jul. 2018. 
LIRA, Roseane Barros da Silva. Educação de jovens e adultos e a formação de professores(as): o uso de uma biblioteca digital como ferramenta de aprendizagem. 2010. 155 f. Dissertação (Mestrado em Educação)- Universidade Federal da Paraíba, João Pessoa, 2010. Disponível em: < https://repositorio.ufpb.br/jspui/handle/tede/4626 >. Acesso em: 10 jun. 2018.

LUCAS, Clarinda Rodrigues. O conceito de biblioteca nas bibliotecas digitais. Informação \& Sociedade: Estudos, João Pessoa, v. 14, n. 2, p. 15-32, jul./dez. 2004. Disponível em: < http://www.brapci.inf.br/index.php/article/view/0000007731/fbf28e05d55e48ad13db1a6aa47e89dc >. Acesso em: 08 set. 2018.

MARTINS, Valéria Bussola O despertar para a leitura por meio de mídias digitais. 2011. $108 \mathrm{f}$. Dissertação (Mestrado em Letras) - Universidade Presbiteriana Mackenzie, São Paulo, 2011. Disponível em: < http://tede.mackenzie.br/jspui/bitstream/tede/2122/1/Valeria\%20Bussola\%20Martins.pdf > . Acesso em: 23 jun. 2018.

MOSÉ, Viviane. A escola e os desafios contemporâneos. 2. ed. Rio de Janeiro: Civilização Brasileira, 2013

RIBEIRO, Ana Elisa Ferreira. Navegar lendo, ler navegando: aspectos do letramento digital e da leitura de jornais. 2008. 243 f. Tese (Doutorado em Linguística) - Faculdade de Letras, Universidade Federal de Minas Gerais, Belo Horizonte, 2008. Disponível em: <

http://www.bibliotecadigital.ufmg.br/dspace/handle/1843/AIRR-7DDQ6S >. Acesso em: 19 maio. 2018.

SEHN, Thaís Cristina Martino. As possíveis configurações do livro nos suportes digitais. 2014. 272 f. Dissertação (Mestrado em Comunicação e Informação) - Faculdade de Biblioteconomia e Comunicação, Universidade Federal do Rio Grande do Sul, Porto Alegre, 2014. Disponível em: < https://lume.ufrgs.br/handle/10183/97246 >. Acesso em: 18 jul. 2018.

SILVA, Edna Cândida da. A biblioteca, o livro e as novas tecnologias: práticas de leitura, memórias e conhecimento. 2014. 98 f. Dissertação (Mestrado em História Cultural)- Pontifícia Universidade Católica de Goiás, Goiânia, 2014. Disponível em: < http://tede2.pucgoias.edu.br:8080/handle/tede/3330 >. Acesso em: 12 jun. 2018. 